\title{
Artikel
}

\section{Ervaringsdeskundigen tegen loondispensatie}

\author{
Hoe intentie, ervaring en rechtmatigheid ver uit elkaar kunnen liggen
}

\author{
J.S. Stad-Ogier*
}

\section{Inleiding}

Mensen met een handicap op gelijke voet laten participeren in de samenleving. Al voor de ratificatie van het VN-verdrag inzake de Rechten van Personen met een Handicap, verder aan te duiden als het IVRPH, was het een belangrijk onderwerp voor de wetgever. Op het gebied van werk zou de invoering van de Participatiewet, in samenhang met de Wet banenafspraak en quotum arbeidsbeperkten (Quotumwet), dit gaan bewerkstelligen. Arbeidsgehandicapten moeten zo veel mogelijk in reguliere banen an het werk, waardoor sociale werkplaatsen niet meer nodig zijn - zo was de gedachte. Drie jaar later blijkt dat de overheidssector achter ligt op het schema van de banenafspraak. Waar de marktsector ruim zevenduizend banen meer heeft gecreëerd dan gepland, blijft de overheid op een kleine 6.500 banen steken, nog geen $65 \%$ van het doel voor 2017. ${ }^{1}$ Er moest dus actie ondernomen worden. Dat werd als reden aangevoerd om een systeem van loondispensatie in het regeerakkoord op te nemen. Het primaire doel was om 'mensen met een arbeidsbeperking meer kansen te geven op duurzaam werk'. ${ }^{2}$ Als actief kernlid bij Wij Staan Op! was ik nauw betrokken bij de lobby om loondispensatie uit de Participatiewet weg te houden.

* J.S. (Jiska) Stad-Ogier is mede-initiatiefnemer, medeoprichter en kernlid van Stichting Wij Staan Op! en bachelorstudent Notarieel recht, Universiteit Leiden.

1. Kamerstukken // 2017/18, 34352, 113, p. 1

2. Kamerstukken // 2017/18, 34352, 98, p. 2.

\section{Het voorstel}

De hoofdlijnennotitie over loondispensatie stelde een regeling voor die de bestaande loonkostensubsidie zou vervangen door een regeling die in de Wajong al langer wordt toegepast. In dit hoofdstuk zal ik de regelingen uiteenzetten.

\subsection{Loonkostensubsidie}

Op dit moment wordt in de Participatiewet loonkostensubsidie toegepast. Deze regeling houdt in dat de gemeente een subsidie an de werkgever verstrekt die het verschil dekt tussen de loonwaarde van een werknemer en het wettelijk minimumloon. De subsidie wordt uitgekeerd aan de werkgever, zodat de werknemer met een handicap één loonstrook ontvangt. Hierin is dan zowel het loon dat de werkgever betaalt naar loonwaarde als de subsidie van de gemeente verwerkt. Voordeel hiervan is dat de werknemer over het gehele loon pensioen opbouwt en sociale premies afdraagt, zodat die in aanmerking kan komen voor een WW-uitkering. Ook ontvangt de werknemer het cao-loon wanneer dit van toepassing is, dit loon boven het minimumloon komt ten laste van de werkgever. ${ }^{3}$ Daarnaast is het voor werkgevers mogelijk om werknemers meer te betalen dan het minimumloon, zonder dat hiermee het recht op loonkostendispensatie komt te vervallen. ${ }^{4}$ Nadeel van loonkostensubsidie is dat er een administratieve last ligt bij de werkgever van de werknemer met een arbeidshandi-

3. www.rijksoverheid.nl/binaries/rijksoverheid/documenten/publicaties/ 2016/02/23/clienten-met-beperking/clienten-met-een-beperking-pdf pdf.

4. Raad van State, Advies W04.16.0302/l, 20 oktober 2016 (www raadvanstate.nl/adviezen/zoeken-in-adviezen/tekst-advies.html?id= $12377 \&$ summary_only=\&q=wajong). 
cap. Over die last is door werkgevers ook geklaagd: het systeem zou te ingewikkeld en belastend zijn. ${ }^{5}$ Dit kan een drempel opwerpen voor werkgevers om iemand met een arbeidshandicap in dienst te nemen.

\subsection{Loondispensatie}

$\mathrm{Bij}$ het instrument loondispensatie betaalt de werkgever de werknemer met een handicap een salaris op basis van de loonwaarde. De werknemer kan vervolgens een aanvulling op dit inkomen aanvragen bij de gemeente: de loondispensatie. De gemeente vult de werknemer aan tot het minimumloon, tenzij er sprake is van een uitzondering. Dit is bijvoorbeeld het geval wanneer iemand een werkende partner heeft of spaargeld. Daarbij wordt de bijstandsnorm aangehouden: ruim 6.000 euro bij alleenstaanden of ruim 12.000 euro bij een fiscaal partner. Omdat de werkgever alleen loon naar loonwaarde uitbetaalt, bouwt de werknemer hierover geen pensioen op, en nauwelijks WW-rechten. De aanvulling vanuit de gemeente geldt niet als loon maar als uitkering, waardoor er geen premies over worden afgedragen, en dus geen pensioenopbouw plaatsvindt.

Voordeel van de regeling is dat het administratieve druk wegneemt bij de werkgevers, waardoor het voor hen interessanter zou moeten worden om mensen met een arbeidshandicap aan te nemen. De staatssecretaris wil hiermee meer banen creëren voor arbeidsgehandicapten. Ook stelt de staatssecretaris in haar plan dat loondispensatie voor een grote groep gehandicapten meer op zou gaan leveren dan de huidige loonkostensubsidie, met name in de situatie waar men parttime werkt. ${ }^{6}$ Het plan zou 500 miljoen euro moeten besparen, dat geld zou vervolgens geïnvesteerd kunnen worden door gemeenten om arbeidsbevorderend beleid uit te voeren.

\section{Nadelen van loondispensatie}

Tegen het voorstel van loondispensatie in de Participatiewet zijn veel argumenten ingebracht, zowel van juridische als van maatschappelijke aard. Ik bespreek de belangrijkste argumenten.

\subsection{Juridische argumenten}

In 2016 ratificeerde Nederland het IVRPH, een VNverdrag dat bijzonder is gericht op de rechten van mensen met een handicap. Doel van het verdrag is kortgezegd om ervoor te zorgen dat gehandicapten wereldwijd mensenrechten kunnen genieten op gelijke voet met anderen. Ongeacht de handicap moet ieders inherente waardigheid worden geëerbiedigd, moet men worden beschermd en moet iedereen de kans krijgen om te participeren. ${ }^{7}$ Belangrijke grondbeginselen daarbij zijn persoonlijke autonomie, onafhankelijkheid en non-discriminatie. ${ }^{8}$ Volgens velen staat het voorstel van loondispen-

\footnotetext{
Kamerstukken I/ 2017/18, 34352, 98, p. 3.

Kamerstukken I/ 2017/18, 34352, 98

Art. 1 IVRPH.

Art. 3 sub a en b IVRPH.
}

satie daarmee op uiterst gespannen voet. Loondispensatie in de Participatiewet zou er immers voor zorgen dat mensen met een arbeidshandicap onder het minimumloon betaald zouden kunnen worden. Wie recht heeft op een aanvulling moet hiervoor zelf de administratieve last dragen, wat niet voor iedereen haalbaar is. Dit is strijdig met het nastreven van persoonlijke autonomie en onafhankelijkheid. Wie geen recht heeft op een aanvulling komt in een financiële situatie waar sparen niet loont en waardoor een ongelijke inkomenspositie ontstaat. Daarbij is het goed voorstelbaar dat een stel of gezin rond zou moeten komen van minder dan twee keer het minimumloon, terwijl de kosten voor het huishouden en levensonderhoud wél voor twee of meer personen is. Cedris, de koepel van sociale werkbedrijven, onderzocht de financiële gevolgen van loondispensatie, en kwam tot de conclusie dat alleen alleenstaanden in kleine deeltijd er financieel op vooruit zouden gaan met de maatregel. Alleenstaanden die iets meer in deeltijd werkten kregen ook meer aanvulling, maar zouden niet extra worden beloond en bouwden geen pensioen op. Alle andere groepen - thuiswonend of samenwonend in alle situaties en alleenstaanden die fulltime werken - zouden door loondispensatie financieel achteruitgaan. ${ }^{9}$

Naast de algemene bepalingen in het IVRPH voorziet het verdrag ook specifiek in eisen over werk en werkgelegenheid voor mensen met een handicap. In artikel 27 IVRPH is onder andere bepaald dat mensen met een handicap recht hebben op werk, op voet van gelijkheid met anderen en met de mogelijkheid in het levensonderhoud te voorzien. $\mathrm{Nu}$ bij loondispensatie het loon alleen naar loonwaarde wordt uitgekeerd, kan gesteld worden dat er ongelijkheid tussen werknemers met en zonder handicap ontstaat, en dat het loon niet voldoende is om in het levensonderhoud te voorzien. Daarnaast ontstaat er een grotere financiële ongelijkheid nu loondispensatie slechts aanvult tot het minimumloon en niet tot het caoloon dat andere medewerkers verdienen. Dat sluit aan op het argument van onvoldoende en ongelijke levensstandaard, dat gewaarborgd is in artikel 28 IVRPH. Immers, mensen met een handicap hebben veelal extra kosten door bijvoorbeeld eigen bijdragen en eigen risico in de zorg.

Ook in het licht van het Internationaal Verdrag inzake Economische, Sociale en Culturele Rechten (IVESCR), is loondispensatie op zijn minst twijfelachtig te noemen. Omdat door loondispensatie ongelijkheid ontstaat tussen gezonde werknemers en werknemers met een arbeidshandicap staat het systeem op gespannen voet met het discriminatieverbod van artikel 2 lid 2 van het verdrag. Daarnaast is uit de artikelen 6 lid 1 (recht op arbeid om in onderhoud te voorzien), artikel 7 sub a (billijke arbeidsvoorwaarden) en artikel 11 lid 1 (behoorlijke levensstandaard) op te maken dat loondispensatie in sommige gevallen voor situaties kan zorgen die tegen het IVESCR indruisen. Daarbij in het achterhoofd de
9. Cedris, infographic Loonkostensubsidie versus Loondispensatie, 25 april 2018 (https://cedris.nl/app/uploads/Cedris-Loonkostensubsidie-vsloondispensatie-pr-5.pdf). 
wetenschap dat veel mensen met een handicap te maken hebben met extra kosten. 'Een achteruitgang in rechten is alleen toegestaan als de staat kan aantonen dat hij een zorgvuldige afweging van alternatieven heeft gemaakt en hier voldoende rechtvaardiging voor is. Dat lijkt hier niet het geval te zijn. Bovendien is deze achteruitgang niet in overeenstemming met het recht op gelijke behandeling', aldus het College voor de Rechten van de Mens. ${ }^{10}$

In Nederlandse wetgeving komt het gelijkheidsbeginsel - artikel 1 Grondwet - direct in gedachten. Hoewel beargumenteerd kan worden dat bij een arbeidshandicap geen sprake is van 'gelijke gevallen' ten opzichte van mensen zonder handicap, creëert loondispensatie een grotere ongelijkheid dan loonkostensubsidie doet. Daartegenover staat dat de werknemer met handicap die evenveel uren werkt dus minder betaald zou krijgen dan een gezonde werknemer. Saillant detail is dat van de gezonde werknemer niet op dezelfde wijze productiviteit gemeten wordt, en dus feitelijk niet vast komt te staan dat de gehandicapte werknemer daadwerkelijk minder produceert. De ongelijkheid van de gevallen is dus aangenomen, waarbij de aanname feitelijk al een vorm van discriminatie is.

\subsection{Maatschappelijke argumenten}

Naast de juridische argumenten tegen het plan werden ook veel maatschappelijke bezwaren aangevoerd. Het meest gebruikte argument hield nauw verband met de hashtag die door Wij Staan Op! wordt gebruikt: \#benikhetnietwaard. De plannen rondom loondispensatie riepen bij veel mensen gevoelens van minderwaardigheid op. Aangedragen werd onder andere het onderscheid dat gemaakt werd in het meten van productiviteit: bij gezonde werknemers wordt dit namelijk niet gedaan. De reden om bij mensen met een arbeidshandicap wel te meten is gestoeld op de aanname dat deze groep minder productief is, waarmee direct al geimpliceerd wordt dat men minderwaardig is.

Een belangrijke reden van de maatregel was volgens de staatssecretaris dat de versimpeling van de systemen, waarbij voor alle nieuwe werknemers met een handicap één regeling zou gelden, zou leiden tot meer werk voor de doelgroep. De achterliggende gedachte hierbij was dat als werkgevers maar met één regeling zouden hoeven werken, het aantrekkelijker voor hen zou zijn om werknemers met een handicap aan te nemen. Het CPB berekende echter dat het effect op werkgelegenheid gering zou zijn. ${ }^{11}$

Ook de financiële beloning van werk en de opbouw van rechten bleek voor velen een heikel punt. Zoals ook bij de juridische argumenten al werd benoemd, ervaren veel mensen met een handicap zwaardere financiële lasten, terwijl ze met de regeling per saldo minder inkomen zouden hebben dan werknemers zonder handicap. Daar

10. https://mensenrechten. $\mathrm{nl} / \mathrm{nl} /$ nieuws/college-plan-loondispensatie-moet -meer-rekening-houden-met-mensenrechten geraadpleegd op 26 september 2018.

11. Centraal Planbureau, Position paper Hoofdlijnennotitie Loondispensatie Participatiewet, 17 april 2018, p. 3. komt bij dat mensen met een handicap vaak veel obstakels moeten overwinnen om aan een baan te komen en op het werk te verschijnen. Pijnpunten daarbij zijn bijvoorbeeld ontoegankelijke openbare ruimten en openbaar vervoer, maar ook de eigen handicap of energiebeperking speelt een rol bij veel mensen die online reageerden. Zoals Pieter Derks scherp formuleerde in zijn column voor Radio 1: 'Dus je hebt een beperking, je hebt toch het doorzettingsvermogen om gewoon naar je werk te gaan, en in plaats van dat je dubbel betaald krijgt voor alle hobbels die je al overwonnen hebt voordat de werkdag überhaupt begonnen is, komt er een mannetje met een formuliertje kijken wat je nou eigenlijk per dag helemaal gedaan krijgt. ${ }^{12}$ Veel mensen met een handicap uitten onvrede over de vooroordelen die er bestaan over gehandicapten, en waren van mening dat de overheid deze vooroordelen alleen maar voedt.

De administratieve last die door de invoering van loondispensatie bij de medewerker met een handicap terecht zou komen werd ook als een belangrijk bezwaar naar voren gebracht. Dit argument was tweeledig. In de eerste plaats stuitte de last op verontwaardiging omdat veel mensen al grote administratieve lasten ervaren door de ingewikkelde regelgeving rondom zorg, begeleiding en hulpmiddelen. Vooral voor mensen die door hun handicap ook een energiebeperking ervaren was dit zeer zwaarwegend. Er werd aangegeven dat mensen soms een 'parttime baan aan administratieve lasten' hebben. ${ }^{13}$ Daarnaast werd vaak aangevoerd dat bedrijven vaak veel beter uitgerust zijn om administratieve taken uit te voeren, zeker waar het gaat om bedrijven die op grond van de Quotumwet arbeidsgehandicapten moeten aannemen. Deze bedrijven kunnen hiervoor werkuren gebruiken of hebben gespecialiseerde werknemers in dienst voor personeelszaken. Wanneer de last op de werknemer komt te liggen, gaat dit ten koste van diens werkbare uren en energie. Een extra probleem zou komen te liggen bij werknemers die door hun handicap niet in staat zouden zijn het overzicht te bewaren in de verschillende inkomens en voorschotten. Wie zich niet zelfstandig kan redden in het oerwoud van regels en administratie zal hier uiteindelijk zelf de prijs voor betalen en mogelijk in schulden terechtkomen. Van een versimpeling van het huidige systeem was dus vanuit het perspectief van de werknemer geen sprake, terwijl die versimpeling wel door het kabinet beoogd werd. ${ }^{14}$

Een ander heikel punt bleken de partner- en de vermogenstoets. Wie een werkende partner heeft, zou geen aanspraak kunnen maken op aanvulling met loondispensatie. Hierdoor kunnen financieel onhoudbare situaties ontstaan. Maar ook voordat de financiën onhoudbaar worden is deze toets een bezwaar: men raakt afhankelijk van de werkende partner, waardoor ook binnen de relatie ongelijkheid ontstaat. Liefde nastreven heeft opeens

12. Pieter Derks over loondispensatie: https://joop.bnnvara.nl/nieuws/ pieter-derks-arbeidsgehandicapten-worden-dubbel-genaaid.

13. Amber Bindels, Spreektekst hoorzitting loondispensatie namens $\mathbf{W i j}$ Staan Op!, 18 april 2018: www.tweedekamer.nl/kamerstukken/detail? $\mathrm{id}=2018 Z 07548 \&$ did=2018D25776.

14. Kamerstukken // 2018/19, 34775, AK, p. 3. 
nóg meer voeten in de aarde nu dit gevolgen kan hebben voor de financiële situatie. Samenwonen of trouwen zou opeens een enorme daling in het inkomen kunnen veroorzaken. Hetzelfde probleem kwam naar voren bij de vermogenstoets: wie wil sparen voor de toekomst of zelfstandigheid komt met loondispensatie bedrogen uit. Omdat gebruik wordt gemaakt van de bijstandsnorm wordt een grens van 6.000 euro aangehouden, voor fiscaal partners het dubbele. Maar wie bijvoorbeeld zou willen sparen voor een aangepaste auto, een aanpassing in huis die niet vergoed wordt of iets anders, komt met 6.000 euro al snel tekort. Wanneer de aanvulling uit loondispensatie stopt bij dit bedrag, moet men het eigen spaargeld weer 'opeten'. Ook dit zorgt weer voor ongelijkheid, maar ook voor afhankelijkheid. Veelal werd hier aangevoerd dat de maatregel daarom uiteindelijk tegen de overheid zou werken. Immers, partners zijn vaak ook mantelzorgers en de kosten voor bijvoorbeeld bijzonder vervoer zouden omlaag gaan als mensen in de gelegenheid worden gesteld te sparen voor eigen vervoer.

\section{Wij Staan Op!}

Stichting Wij Staan Op! had een belangrijke rol bij het verzet tegen loondispensatie in de Participatiewet. In dit hoofdstuk zal ik het ontstaan en de werkwijze van Wij Staan Op! uiteenzetten, en een toelichting geven op de lobby die tegen loondispensatie gevoerd is door deze stichting.

\subsection{Ontstaan}

Wij Staan Op! ontstond begin 2015 naar aanleiding van de invoering van de Participatiewet. De twee initiatiefneemsters ${ }^{15}$ ontmoetten elkaar naar aanleiding van initiatieven die zij ondernamen. Pauline Gransier kreeg ook de gelegenheid om de Kamer toe te spreken over de implicaties van de Participatiewet. ${ }^{16}$ Zelf werkte ik als eerstejaars student rechtsgeleerdheid aan een website die de wet in begrijpelijke taal moest gaan uitleggen. We vonden elkaar via sociale media en spraken over de mogelijkheid om de handen ineen te slaan voor een inclusief Nederland. Hieruit ontstond in april $2015 \mathrm{Wij}$ Staan Op!. Het doel van Wij Staan Op! was direct duidelijk: een inclusief Nederland, bezien vanuit het perspectief van en bewerkstelligd door de ervaringsdeskundigheid van jongvolwassenen met een fysieke handicap. Het eerste middel waarmee Wij Staan Op! dit doel wilde gaan bereiken was het Manifest voor Vrijheid, Gelijkheid en Menselijkheid - een modern pleidooi met een knipoog naar de Franse revolutie. Het manifest schreven wij met de eerste tien jongvolwassenen die betrokken waren bij Wij Staan Op!, vanuit onze ervaringen. ${ }^{17}$ Over de twaalf stellingen werden we het snel eens. Het zijn de kernpunten voor inclusie als het gaat om mensen

15. Pauline Gransier en de auteur.

16. Zie haar website: http://paulinegransier.com/.

17. www.wijstaanop.nl/manifest.html, inmiddels vervangen door het handvest. met een levenslange en levensbrede handicap. De punten zijn geschreven vanuit onze ervaring en behoefte, aangevuld met voorbeelden uit de toenmalige situatie en een suggestie hoe het beter kan. De punten variëren van vertrouwen en beschikbaarheid van medische verklaringen, tot bejegening en fysieke toegankelijkheid.

$\mathrm{Na}$ het schrijven van het manifest hebben we dit naast het IVRPH gelegd. Bijzonder was dat direct bleek dat onze punten vrijwel integraal overeenkwamen met het IVRPH, met aanvulling van voorbeelden en meer toegespitst op Nederland. De ratificatie van het IVRPH werd dan ook het eerste grote doel van Wij Staan Op!. Daartoe startten we met het opbouwen van een netwerk op sociale media en in onze (politieke) omgeving. In januari 2016 startten we met de twitteractie \#jekomternietin. Met de hashtag vroegen we aandacht voor ontoegankelijkheid in de breedste zin van het woord: niet alleen fysieke obstakels, maar bijvoorbeeld ook obstakels in regelgeving en bejegening konden gemeld worden met deze hashtag. Dit werd een groot succes, de pakkende tekst zorgde voor enorme bekendheid, waarmee we het IVRPH opnieuw op de radar van Nederland kregen. Door samenwerking met belangenorganisaties die hier al jaren aan werkten, konden we de maatschappelijke en politieke druk opvoeren, zodat het verdrag in januari door de Tweede Kamer, ${ }^{18}$ en in april door de Eerste Kamer werd goedgekeurd. ${ }^{19}$ Een maand na ratificatie trad het verdrag op 14 juli 2016 in werking, waarmee het werk van Wij Staan Op! eigenlijk pas echt begon.

\subsection{Werkwijze}

Het originele manifest is inmiddels geüpdatet tot een handvest, dat meer ruimte laat voor aanpassingen. Door te werken aan de uitvoering van het IVRPH werken we tegelijk aan het uitvoeren van ons handvest en manifest, nu dat qua onderwerpen zeer goed op elkaar aansluit. Dat uitwerken doen we middels maatschappelijke en politieke lobby. Soms is dit heel zichtbaar, zoals bij \#jekomternietin of de acties tegen loondispensatie in de Participatiewet. Ook zijn veel van onze werkzaamheden minder zichtbaar. Je kunt daarbij denken aan onderwerpen die minder media-aandacht krijgen, werk achter de schermen of wanneer we er simpelweg niet aan toe komen om al onze werkzaamheden te delen met onze volgers. Ook kan de aanpak verschillen per onderwerp. Voor grote onderwerpen zoals toegankelijk openbaar vervoer of (voorbereiding van) politieke zaken hebben we vaste teams binnen de kerngroep, die nog altijd bestaat uit maximaal tien jongvolwassenen. Hiermee houden we de lijnen kort, zodat we efficiënt te werk kunnen gaan.

Inclusie is een enorm veelomvattend doel, hoewel we onze expertise al redelijk hebben ingeperkt door te kijken vanuit jongvolwassenen met een fysieke handicap. Veel van onze acties overlappen ook gedeeltelijk met andere groepen en belangenorganisaties, zoals dat ook
18. www.tweedekamer.nl/kamerstukken/wetsvoorstellen/detail?id= 2014Z13574\&dossier $=33990$.

19. www.eerstekamer.nl/wetsvoorstel/33992_goedkeuring_verdrag_ inzake. 
bij loondispensatie het geval was. Dat wordt uiteraard niet uit de weg gegaan. We bepalen welke zaken we oppakken aan de hand van een aantal handvatten: de toepasselijkheid op ons handvest - dit houden we aan als onze subdoelen - de actualiteit en de haalbaarheid: hebben we de mensen en de kennis in huis of om ons heen om zaken echt aan te pakken. Daarnaast wordt gekeken naar de manier waarop zaken het beste aangepakt kunnen worden. Daarbij is politieke lobby een belangrijk instrument. Vaak aangevuld met maatschappelijke lobby via onze actieve socialemediakanalen.

Wij Staan Op! gaat altijd uit van een constructieve dialoog, waarmee we samen werken aan verbetering. Naast die constructieve dialoog, of om zo'n dialoog aan te kunnen gaan is het soms wel nodig om zogezegd actie te voeren.

\subsection{In actie tegen loondispensatie}

De lobby tegen de inzet van loondispensatie in de Participatiewet is voor Wij Staan Op! een nieuwe stap geweest. In de snelle reactie op de plannen is met een klein team gehandeld, waarna het gehele kernteam de petitie verder heeft gedragen. Daarbij sloten we uiteraard wel weer aan met een pakkende hashtag - \#benikhetnietwaard - en een uitgebreide politieke lobby. Het was hierbij voor ons in het bijzonder van belang om te laten zien hoe groot het tegengeluid was. Daarvoor bleek een onlinepetitie een goed middel.

Het verzet tegen loondispensatie is zowel ideologisch als praktisch passend bij Wij Staan Op!. Ideologisch past loondispensatie natuurlijk niet bij de gelijkwaardigheid en inclusie die de stichting nastreeft. Daarbij vond het verzet vooral grondslag in de stelling van het handvest: 'kansen op de arbeidsmarkt moeten voor iedereen gelijk zijn'. Daarbij is het van belang dat niet alleen de kansen op een baan gelijk zijn, maar ook dat mensen gewaardeerd worden voor wat ze kunnen, met de capaciteiten en kwaliteiten van het individu als uitgangspunt. ${ }^{20}$ Loondispensatie staat daar feitelijk lijnrecht tegenover. Het uitgangspunt is dat iemand met een arbeidshandicap naast mogelijke praktische bezwaren - denk aan een aanpassing op de werkplek of een parttime baan in verband met een energiebeperking - ook minder productief is dan een reguliere werknemer. Daarbij is de waardering voor het werk ook nog eens lager: het salaris. Omdat het plan een hoofdlijnennotitie betrof, was over actualiteit geen vraag, maar was er ook nog ruimte voor verbetering. Het is immers moeilijker een bestaande wet aan te passen of terug te draaien, dan een wet in wording bij te schaven of in dit geval: te verwerpen. Daarbij hebben we gemerkt dat het laten zien van een grote achterban voor de politiek reden geeft om in gesprek te gaan: de petitie was daarvoor een goed middel. ${ }^{21}$

Een bijzondere toevalligheid was dat vrijwel tegelijk met de petitie de open brief van Noortje van Lith aan minister-president Mark Rutte viraal ging. Daarop is gelijk een samenwerking aangegaan: Wij Staan Op! besteedde aandacht aan de brief van Noortje, en Noortje voegde de petitie toe aan haar berichten. Naast versterking van elkaars acties leverde dit soms ook enige verwarring op bij mensen die dachten dat Noortje en Wij Staan Op! één waren. Dat leverde als voordeel op dat Wij Staan Op! telefoontjes en berichten aan kon nemen voor Noortje, waardoor zij enigszins ontlast werd.

Naast de petitie en de brief is ook de hashtag \#benikhetnietwaard van grote waarde geweest. Deze veelzeggende tekst sprak veel mensen aan, waardoor de maatschappelijke belangstelling voor het onderwerp groeide, en daarmee ook het maatschappelijk verzet. Daarbij werd de lobby gesteund door vele bekende Nederlanders - denk aan Pieter Derks, Claudia de Breij, Ionica Smeets, Dolf Jansen - maar ook vele politici, belangenorganisaties, en (column)schrijvers. Ook dit droeg bij aan de maatschappelijke bekendheid met de plannen, waardoor ook de petitie steeds bekender werd, en meer mensen zich aansloten. Een ander belangrijk punt was de media-aandacht die loondispensatie en het verzet daartegen kreeg. Verschillende kernleden verschenen op televisie, lieten zich horen op de radio of werden geinterviewd voor kranten.

Hiermee werd ook politieke aandacht getrokken, waardoor Wij Staan Op! al vroeg in het proces aan tafel zat bij verschillende politieke partijen om van gedachten te wisselen. Ook werd de stichting uitgenodigd bij hoorzittingen en overleggen van belangenpartijen. ${ }^{22}$ Hierbij heeft Wij Staan Op! laten zien dat er, naast het laten horen van maatschappelijk geluid, ook een duidelijke (juridische) argumentatie aanwezig was voor het verzet. Tijdens zulke politieke overleggen is het ook beter mogelijk een genuanceerd beeld te schetsen van de problematiek en de voorgestelde oplossingen hiervoor.

Al met al hebben we met Wij Staan Op! bij het verzet tegen loondispensatie gekozen voor een heel brede aanpak. Door vele paden tegelijk te bewandelen in een goed op elkaar afgestemde opzet werd de aandacht voor loondispensatie gemaximaliseerd. Met succes, want uit de intrekking van het plan bleek niet alleen dat het maatschappelijk verzet te groot was, maar ook dat de praktische onuitvoerbaarheid bewezen was door tegenstanders waar Wij Staan Op! zich onder mag rekenen.

\section{Conclusie}

Loondispensatie als aanvullende uitkering is geweerd uit de Participatiewet door de inzet van vele partijen met vele argumenten, van maatschappelijke ongewenstheid tot de toetsing aan belangrijke internationale verdragen. Daarbij rijst ook de vraag: hoe nu verder? Duidelijk is dat de bestaande loonkostensubsidie voor veel van de betrokken partijen de voorkeur heeft, maar versimpeld moet worden. Administratieve lasten voor werkgevers moeten omlaag, regelgeving moet eenduidiger en simpe-

20. Wij Staan Op!, Handvest voor vrijheid, gelijkheid en menselijkheid, Utrecht 2017, p. 7.

21. De petitie werd 88.762 keer getekend.

22. www.tweedekamer.nl/debat_en_vergadering/commissievergaderingen/ details?id=2018A01586 
ler worden. Daarnaast is het van groot belang dat toekomstige plannen getoetst worden aan de internationale verplichtingen die Nederland heeft. Niet in de laatste plaats aan het IVRPH, dat vrij recent geratificeerd is en daarom juist nu zijn meerwaarde kan bewijzen. Daarbij staat de vraag van werk en loon voor arbeidsgehandicapten zeker niet op zich. Er zijn veel meer regelingen die administratief (zwaar) belastend blijken voor betrokkenen, zeker wanneer het gaat over mensen met een handicap. Belangrijk is om helder te houden waar het om gaat: mensen met een handicap volwaardig laten participeren. Dit is niet alleen een verplichting vanuit het IVRPH, maar is ook een aanwinst voor de samenleving. Als het gaat over de vraag hoe mensen met een arbeidshandicap aan het werk moeten komen, is het goed om te leren van de marktsector die nu al boven de norm presteert, in plaats van het probleem te leggen bij een regeling die relatief goed functioneert.

Wat betreft de Participatiewet in het bijzonder zou het goed zijn de regels en de doelen van de wet nogmaals onder de loep te nemen. De wet heeft in het verleden al voor veel verzet gezorgd, en lijkt dat te blijven doen. Met enige regelmaat verschijnen er berichten over regelingen die participatie juist lijken tegen te gaan, denk hierbij aan het recente bericht dat de wet de baankans van arbeidsgehandicapten juist heeft verkleind. ${ }^{23}$ Het is daarom van belang om te onderzoeken of de wet doet waarvoor hij is ontworpen, en of de wet wel in overeenstemming is met bijvoorbeeld het IVRPH. In 2014 hebben belangenorganisaties al opgeroepen om het voorstel voor de Participatiewet langs de verplichtingen uit het IVRPH te leggen. Nu de staat zich volledig aan het verdrag gebonden heeft, dient iedere ingrijpende wet die mensen met een handicap betreft aan het verdrag getoetst te worden. Daarnaast pleit ik voor de intensieve inzet van ervaringsdeskundigheid bij het ontwikkelen van regelingen en wetten. Daarbij is niet alleen de stem van werkgeversorganisaties van belang, maar juist ook die van mensen met een handicap zelf. Ervaringsdeskundigheid is van enorme waarde, en geeft menselijk inzicht in een wereld van papieren en regels. Het draagt bij aan de efficiëntie van processen, en uiteindelijk van regelgeving, wanneer betrokken partijen zich kunnen uitspreken. 